\title{
Transnasal endoscopic biopsy of a parapharyngeal heterotopic pleomorphic adenoma
}

\begin{abstract}
Pleomorphic adenomas originating from the minor salivary glands are rare in the parapharyngeal space, although they are the most common benign tumors in this area followed by paragangliomas, and the most common benign salivary gland tumors. In this paper we are reviewing a case of parapharyngeal heterotopic pleomorphic adenoma in a 58years old female where biopsy for pathologic verification was taken using nasal endoscopy through the nasopharynx reaching the tumor in the parapharyngeal space. This technique is presenting a new tool that can be used for pathologic verification. Total surgical resection is, till today, the preferred treatment for pleomorphic adenomas.
\end{abstract}

Keywords: transnasal endoscopic biopsy, salivary glands, parapharyngeal space, paragangliomas, nasopharyngolaryngoscopy, oropharynx, eustachian tube, submandibular, sublingual
Volume 5 Issue 2 - 2016

\author{
Mazen Hammoud, Bachar Skaff , Hamdi \\ Hamiyyeh \\ Otolaryngology Head Neck Surgery specialist Hammoud \\ Hospital University Medical Center, Lebanon
}

\begin{abstract}
Correspondence: Mazen Hammoud Otolaryngology Head Neck Surgery Specialist Head of department Hammoud Hospital University Medical Center HHUMC Ghassan HAMMOUD Street Saida, Lebanon, Tel 0096|7723888-1957, Email Hammoudmazen@hotmail.com
\end{abstract}

Received: May 27, 2016 | Published: December 22, 2016

\section{Introduction}

The parapharyngeal space is a pyramidal area bounded by the skull base superiorly, the hyoid bone inferiorly, the pterygomandibular raphe anteriorly, the vertebral fascia posteriorly, the medial pterygoid laterally, and the superior constrictor muscle medially. The space contains both the pre-styloid and post-styloid compartments, and pathology in this area is based on these anatomic structures. Salivary gland tumors are the most common tumors in the parapharyngeal space and are the main consideration in the differential diagnosis.

Parapharyngeal space neoplasms can arise de novo or extend from surrounding structures. In the case of benign salivary gland tumors, it is hypothesized that they arise de novo from rests of salivary tissue in the parapharyngeal space. Both MRI and CT scanning are useful in assessing masses of the parapharyngeal space. ${ }^{1,2}$

\section{Case study}

A 58year old female previously healthy was referred to our department in Hammoud Hospital University Medical Center, Saida, Lebanon, with a right painless upper neck mass increasing in size over the last few months accompanied with acute right nasal obstruction and minor dysphagia. Physical examination revealed a right upper neck mass, deep, firm, non tender and nonpulsatile. Oral examination shows a right soft palatal bulge with shifting of the uvula toward the left side. We did a fiberoptic nasopharyngolaryngoscopy which revealed bulging of the normal mucosa extending from the nasopharynx superiorly just below the Eustachian tube opening above to the oropharynx below and reaching the right tonsillar space that is also pushed medially.

A CT scan of the neck following IV administration of contrast material was performed and showed that there is evidence of relatively large $5 * 3 \mathrm{~cm}$ hypodense parapharyngeal mass lesion medial to the deep portion of the right parotid gland reaching the level of the right side of the nasopharynx and oropharynx causing compression of the nasopharynx airway with narrowing of its lumen and extending to reach the base of the tongue and right side of the oropharynx causing compression and narrowing of its lumen.

Under general anesthesia, using a 30degree rigid nasal endoscope, a $0.5 \mathrm{~cm}$ long incision was made horizontally just under the Eustachian tube opening, preparation was performed around $1 \mathrm{~cm}$ deep until we reached a whitish mass of which multiple biopsies were taken and sent for histopathological examination which documented a pleomorphic adenoma. $^{3}$

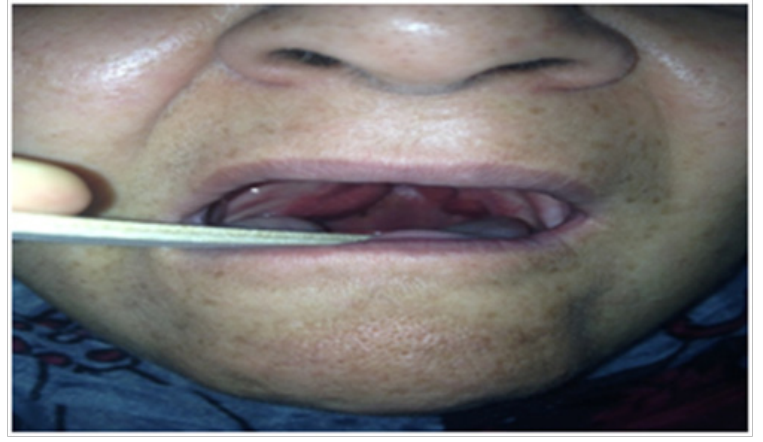

Figure I Right side soft palatal bulge with shifting of the uvula toward the left side.

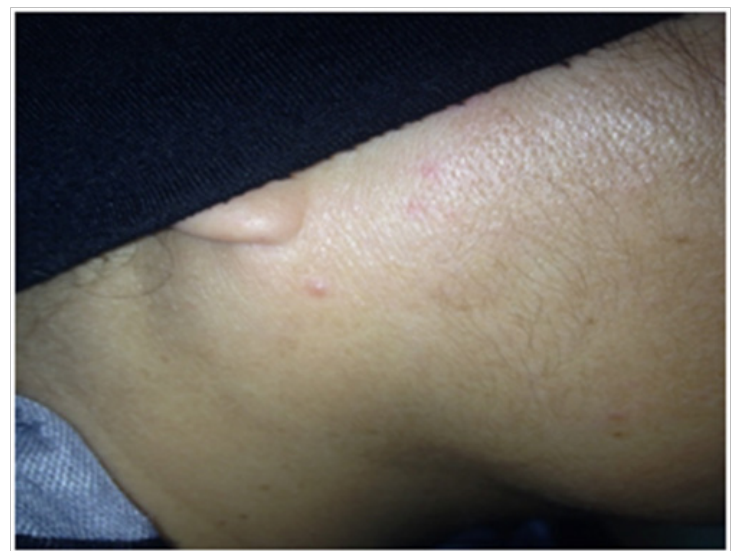

Figure 2 Right side upper neck mass.

\section{Discussion}

The salivary neoplasms account for less than 3\% of all head and neck tumors and they account for less than $0.1 \%$ of all cancer 
deaths. The relative incidence of salivary gland tumors is estimated to be that for every 100 parotid tumors, there are 10 submandibular tumors, 10 minor salivary tumors, and 1 sublingual tumor. The parotid, submandibular, and sublingual glands are often referred to as the major salivary glands, whereas the minor salivary glands are numerous and are present in the deeper submucosal planes of the oral cavity (especially the lip and hard and soft palates), pharynx, external auditory canal, lower neck, mandible, nose and paranasal sinuses. These minor salivary glands are not typically identified on imaging unless they are pathologically enlarged or involved with tumor, of which they are an important tissue of origin.

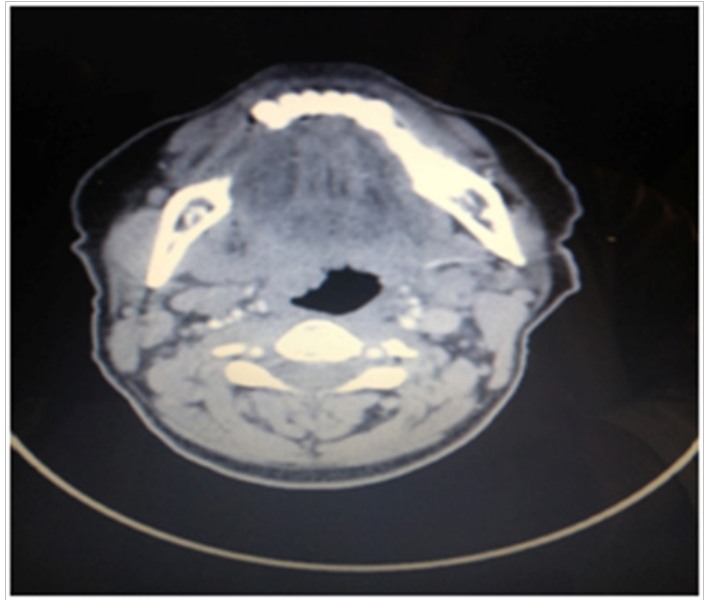

Figure 3 Tumor compressing the oropharynx.

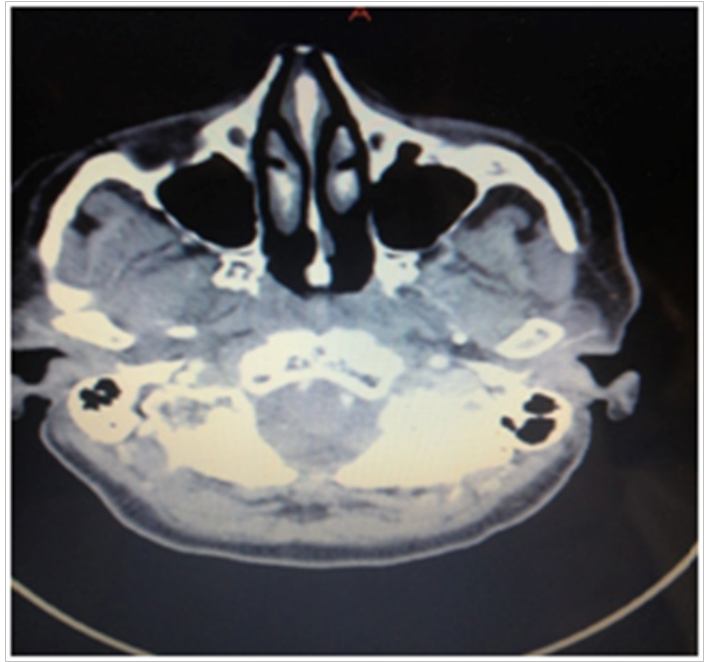

Figure 4 Tumor compressing the nasopharynx.

Pleomorphic adenomas, also called benign mixed tumor most frequently arise from the major salivary glands where it constitutes about $75 \%$ of all benign tumors of them. Only $6.5-8 \%$ of them originate in the minor salivary glands. Diagnosis of pleomorphic adenoma in the neck space is usually done by fine needle aspiration, while nasal endoscopic surgery can be used as an additional tool in selected cases. ${ }^{4,5}$
Successful resection of the lesions can be accomplished by both a transparotid transcervical approach and strictly a transcervical approach. Mandibulotomy is generally not necessary except in large tumors where wide exposure is necessary for the control of vessels. Warthin's tumors and other neurogenic tumors as well as salivary malignancies have been described in parapharyngeal space but are much less common. ${ }^{6-9}$

\section{Conclusion}

Pleomorphic adenomas rarely involve the neck. Biopsy for pathologic verification can be performed in selected cases by using transnasal endoscopy as in this case or by fine needle aspiration. Although the prognosis is good, the choice of treatment is the complete resection of the tumor. But, because of recurrence potential of this tumor, long-term follow-up is necessary.

\section{Acknowledgments}

None.

\section{Conflicts of interest}

Author declares there are no conflicts of interest.

\section{Funding}

None.

\section{References}

1. Cummings WC, Flint PW. Cummings otolaryngology head \& neck surgery. (5th edn), Mosby Elsevier, Philadelphia, USA. 2010.

2. Shumrick DA, Paparella MM. Otolaryngology. WB Saunders Company, Philadelphia, USA. 1991.

3. Unlu HH, Celik O, Demir MA, et al. Pleomorphic adenoma originated from the inferior nasal turbinate. Auris Nasus Larynx. 2003;30(4):417-420.

4. Vegari S, Naderpour M, Hemmati A, et al. Pleomorphic Adenoma of the Cervical Heterotopic Salivary Gland: A Case Report. Case Rep Otolaryngol. 2012; 2012:470652.

5. Karakus MF, Ozcan KM, Dere H. Endoscopic resection of pleomorphic adenoma of the nasal septum. Tumori. 2007;93(3):300-301.7

6. Peng P, Har-El G. Anatomy and physiology in Essentials of Otolaryngology. In: Lucente FE \& Har-El G (Eds.), Lippincott Williams \& Wilkins (5th edn), Philadelphia, USA. 2004. p. 3-39.

7. Daniel E, McGuirt WF. Neck masses secondary to heterotopic salivary gland tissue: a 25 -year experience. Am $J$ Otolaryngol. 2005;26(2):96-100?

8. Som PM, Shugar JM, Sacher M, et al. Benign and malignant parotid pleomorphic adenomas: CT and MR studies. $J$ Comput Assist Tomogr. 1988;12(1):65-69.

9. Ceylan A, Celenk F, Poyraz A, et al. Pleomorphic adenoma of the nasal columella. Pathol Res Pract. 2008;204(4):273-276. 